\title{
Factors that influence the interaction of Campylobacter jejuni with cultured mammalian cells
}

\author{
M. E. KONKEL, M. D. CORWIN, L. A. JOENS* and W. CIEPLAK
}

Laboratory of Vectors and Pathogens, Department of Health and Human Services, National Institutes of Health, National Institute of Allergy and Infectious Disease, Rocky Mountain Laboratories, Hamilton, MT 59840 and " Department of Veterinary Science, University of Arizona, Tucson, AZ 85721, USA

\begin{abstract}
Summary. Although Campylobacter jejuni is now recognised as a common enteric pathogen, the mechanisms by which this organism produces enteritis remain ill-defined. It has been proposed that its abilities to adhere to and enter epithelial cells represent properties essential to virulence. However, the characteristics of these interactions and factors that may influence the association of $C$. jejuni with epithelial cells are incompletely described. We have determined that the ability of $C$. jejuni to bind to epithelial cell lines in vitro is significantly affected by the growth temperature and growth stage of the bacteria, but not by growthmedium composition. Binding of $C$. jejuni to cultured cells is not affected by temperature or phylogenetic origin of the target cell, and exhibits a non-uniform or patchy distribution. In contrast, internalisation is markedly diminished at low temperature, appears to involve active invagination of the target cell membrane via pseudopod formation, and is maximal when cells of human origin are employed.
\end{abstract}

\section{Introduction}

Campylobacter jejuni is a significant cause of enteritis in man. ${ }^{1}$ However, the pathogenic mechanisms associated with $C$. jejuni-mediated enteritis are unclear and the virulence factors of $C$. jejuni remain ill-defined. Proposed virulence factors include adherence, invasiveness and the production of toxins. ${ }^{2-5}$ Of these attributes, the ability of $C$. jejuni to adhere to host cells has been suggested to be essential for virulence. ${ }^{6}$ For example, Fauchere et al. ${ }^{7}$ found that $C$. jejuni isolates from patients with fever and diarrhoea more frequently bound to mammalian cell lines than isolates from individuals without diarrhoea or fever.

The goal of most investigations of the ability of $C$. jejuni to bind to mammalian cells has been the identification of potential adherence factors or adhesins. Possible adhesins include outer-membrane proteins, flagella and lipopolysaccharide, ${ }^{6,8,9}$ but their roles remain largely speculative. Although investigators have been attempting to identify outer-membrane components that play a role in bacterial adherence, bacterial growth conditions and their relationship to the expression of adherence and other factors remain largely unexplored. Indeed, there is little discussion in published works of the influence of conditions used for the culture of $C$. jejuni on experimental observations concerning adherence and internalisation. Buck et al..$^{10}$ suggested that the age of

Received 20 June 1991 ; revised version accepted 13 Sept. 1991 the culture might influence various phenotypic properties of $C$.jejuni. They reported that, as the bacteria age or mature, their morphology alters from the typical spiral-shaped appearance to coccoid forms, which predominate in older cultures and are believed to represent a degenerate state produced by unfavourable growth conditions. Furthermore, the characteristics of C. jejuni interactions with cultured cells, including the kinetics of attachment and internalisation and other physical properties, are incompletely described. This lack of information has hampered comparisons with the properties of other, better-described invasive bacterial pathogens.

In the present study, factors influencing the association of $C$. jejuni with cultured mammalian cells were examined in vitro. The methodology allowed direct observation of the cultured cells and quantitation of cell-associated bacteria.

\section{Materials and methods}

\section{Bacterial strains}

C. jejuni isolates M129 and T6644 were obtained from Dr K. Ryan (University Medical Center, Tucson, AZ) as primary clinical isolates from patients with fever and bloody diarrhoea. C. jejuni isolate 87-95 (previously designated A3249) was obtained from Dr M. Blaser (Vanderbilt University, Nashville, TN) and has been described previously. ${ }^{11} C$. jejuni isolates were stored frozen at $-70^{\circ} \mathrm{C}$ in citrated bovine blood 
$5 \% \mathrm{v} / \mathrm{v}$ as described elsewhere. ${ }^{22}$ The stock cultures were quickly thawed in a water bath at $37^{\circ} \mathrm{C}$ and $1-2$ drops of the suspension were added to the surface of a Mueller-Hinton (MH) agar plate containing citrated bovine blood $5 \% \mathrm{v} / \mathrm{v}$ (MH blood agar). Cultures were incubated at $37^{\circ} \mathrm{C}$ in BBL Gas-Pak jars with BBL CampyPak Plus packets containing a palladium catalyst (Becton Dickinson, MD). The bacterial cultures were routinely passaged every 24 or $48 \mathrm{~h}$. No bacterial isolate was passaged more than 12 times after primary isolation. Unless otherwise stated, all cultures were subcultured $24 \mathrm{~h}$ before use in experimental assays. The bacteria were harvested from MH blood agar plates with phosphate-buffered saline (PBS) and centrifuged at $6000 \mathrm{~g}$ for $10 \mathrm{~min}$. Supernatant fluids were removed and the pellets were suspended in Eagle's Minimal Essential Medium (MEM) supplemented with fetal bovine serum (FBS) $1 \% \mathrm{v} / \mathrm{v}$ for use in experiments.

\section{Mammalian cell culture}

Stock cultures of INT 407 (human embryonic intestine, ATCC CCL 6), HEp-2 (human laryngeal epidermoid carcinoma, ATCC CCL 23), 293 (transformed human embryonic kidney, ATCC 1573-CRL), HeLa (human epithelial cervical carcinoma ATCC CCL2), Vero (African green monkey kidney, ATCC CCL 81), CHO-K1 (Chinese hamster ovary, ATCC CCL 61), and MDCK (Madin-Darby canine kidney, ATCC CCL 34) cell lines were obtained from the American Type Culture Collection. INT 407, HEp-2, 293, Vero, HeLa and MDCK cells were grown as monolayers in MEM supplemented with FBS $10 \% \mathrm{v} / \mathrm{v}$. CHO-K1 cells were grown in Ham's F12 medium with FBS $10 \% \mathrm{v} / \mathrm{v}$. All cell lines were grown without antibiotics. The cultures were incubated in a $\mathrm{CO}_{2} 5 \% \mathrm{v} / \mathrm{v}$ incubator at $37^{\circ} \mathrm{C}$. For experimental assays, cultures were harvested by mild trypsinisation and seeded into 24-well tissue culture trays at $7.0 \times 10^{4}$ cells/well and incubated for $24 \mathrm{~h}$ in a $\mathrm{CO}_{2}$ incubator at $37^{\circ} \mathrm{C}$.

\section{Adherence and internalisation assays}

Semi-confluent monolayers of cultured cells in 24well plates were rinsed once with pre-warmed MEM supplemented with FBS $1 \% \mathrm{v} / \mathrm{v}$. The medium overlying the monolayers was then removed and the cultures were inoculated with $5 \times 10^{7} \mathrm{cfu}$ of $C$. jejuni in $0.5 \mathrm{ml}$ of MEM supplemented with FBS $1 \% \mathrm{v} / \mathrm{v}(c$. $7 \times 10^{2}$ bacteria/mammalian cell) unless otherwise indicated. The plates were centrifuged at $600 \mathrm{~g}$ for $10 \mathrm{~min}$ to enhance the association of the bacteria with the cells and to minimise motility-dependent effects. ${ }^{13}$ Bacteria were allowed to adhere to the cells for $30 \mathrm{~min}$ at $37^{\circ} \mathrm{C}$ in a $\mathrm{CO}_{2}$ incubator. After incubation, the monolayers were rinsed three times with PBS and the cells were lysed with sodium deoxycholate $0.5 \% \mathrm{w} / \mathrm{v}$. Adherent bacteria were counted by plating serial dilutions of the suspensions on MH blood agar plates and counting the resulting colonies. A modification of this assay was used to study the effect of temperature on the association of $C$. jejuni with INT 407 cells. Bacterial pellets were suspended in Dulbecco's PBS, to avoid changes in $\mathrm{pH}$ associated with the different incubation conditions, and diluted to $1 \times 10^{8} \mathrm{cfu} / \mathrm{ml}$. The cell monolayers were inoculated with $0.5 \mathrm{ml}$ of the $C$. jejuni suspension and then incubated for the appropriate amount of time at various temperatures under ambient atmospheric conditions. The number of adherent bacteria was determined as described above.

To examine internalisation, the cell monolayers in 24-well plates were rinsed once with pre-warmed MEM supplemented with FBS $1 \% \mathrm{v} / \mathrm{v}$ and each well was inoculated with $5 \times 10^{7} \mathrm{cfu}$ of $C$. jejuni. The plates were then centrifuged at $600 \mathrm{~g}$ for $10 \mathrm{~min}$. Each 24 well plate was incubated for $3 \mathrm{~h}$ at $37^{\circ} \mathrm{C}$ in a $\mathrm{CO}_{2}$ incubator to allow the bacteria to adhere to and internalise within the epithelial cells. After incubation, the monolayers were rinsed three times with MEM and then incubated in MEM containing FBS $1 \% \mathrm{v} / \mathrm{v}$ and gentamicin sulphate $250 \mu \mathrm{g} / \mathrm{ml}$ for $3 \mathrm{~h}$ at $37^{\circ} \mathrm{C}$ in a $\mathrm{CO}_{2}$ incubator. After incubation, the infected monolayers were washed three times with PBS and lysed with sodium deoxycholate $0.5 \% \mathrm{w} / \mathrm{v}$. The number of internalised bacteria was determined by diluting the suspensions in PBS and counting colonies on $\mathrm{MH}$ blood agar plates. When the effect of temperature on internalisation was examined, Dulbecco's PBS was used instead of MEM.

The assays were performed a minimum of three times each in triplicate or quadruplicate. The $95 \%$ confidence intervals of the means for individual experiments were calculated from the SEM and the critical values of the Student's $t$-distribution for the corresponding number of replicates. Statistical comparisons were done with the unpaired Mann-Whitney twosample tests.

\section{Preparation of hyperimmune serum}

New Zealand White rabbits were immunised at 2week intervals with formalin-inactivated $C$. jejuni isolate $87-95$ by subcutaneous injection. After four immunisations, serum was collected and the presence of anti- $C$. jejuni antibodies was determined by indirect immunfluorescence and by immunoblotting.

\section{Immunofluorescence assays}

Indirect immunofluorescence was performed on HEp-2 cell monolayers essentially as described by Knutton et al. ${ }^{14}$ Sterile, round coverslips $(13 \mathrm{~mm})$ were placed in each well of a 24-well plate and seeded with $3.75 \times 10^{4}$ cells. The cells were incubated at $37^{\circ} \mathrm{C}$ for $24 \mathrm{~h}$ in a $\mathrm{CO}_{2}$ incubator and washed once with MEM containing FBS $1 \% \mathrm{v} / \mathrm{v}$ immediately before the assay. The monolayers were inoculated with bacteria 
and plates were centrifuged as described for the internalisation assay. Wells containing semi-confluent monolayers of HEp-2 cells without added bacteria served as controls. After centrifugation, the coverslips were processed immediately to assess the number of cell-associated bacteria. The cell monolayers were washed three times with PBS and fixed for $20 \mathrm{~min}$ with formaldehyde $3 \% \mathrm{w} / \mathrm{v}$. After three washes with PBS, cells were permeabilised with Triton X-100 $0.1 \% \mathrm{v} / \mathrm{v}$ in PBS for $5 \mathrm{~min}$. The cell monolayers were then washed three times with PBS, treated with a hyperimmune rabbit antibody (diluted 1 in 100 in PBS) against $C$. jejuni for $45 \mathrm{~min}$ at $37^{\circ} \mathrm{C}$, and rinsed three times with PBS. Each coverslip was then treated with the $F\left(a b^{\prime}\right)_{2}$ fragments of rhodamine-conjugated goat anti-rabbit IgG (final concentration $10 \mu \mathrm{g} / \mathrm{ml}$ ) for $30 \mathrm{~min}$ at $37^{\circ} \mathrm{C}$. In some experiments, the cells were incubated for a further $3 \mathrm{~h}$ at $37^{\circ} \mathrm{C}$ in a $\mathrm{CO}_{2}$ incubator to examine the effects of $C$. jejuni adherence on cellular actin distribution. ${ }^{13,14}$ After three washes with PBS, the cells were treated with a solution of fluorescein isothiocyanate-conjugated phalloidin (Sigma) $5 \mu \mathrm{g} / \mathrm{ml}$ in PBS for $20 \mathrm{~min}$ at room temperature to stain filamentous actin. For all experiments, the coverslips were washed three times with PBS and mounted in glycerol-PBS. The samples were examined with a Leitz fluorescence microscope.

\section{Scanning electronmicroscopy}

Cell monolayers were grown on 13-mm round coverslips as described for the immunofluorescence assays. After inoculation and centrifugation of the plates, the monolayers were incubated in a $\mathrm{CO}_{2}$ incubator at $37^{\circ} \mathrm{C}$. The assays were terminated by washing each well three times with PBS and fixing the cell monolayers with glutaraldehyde $2.5 \% \mathrm{w} / \mathrm{v}$. The coverslips were rinsed twice with deionised water (5 min each wash) and transferred through a graded series of ethanol washes $(15,30,50,70,95$ and $100 \%$ $\mathrm{v} / \mathrm{v})$. After dehydration, each sample was dried in a critical point dryer (Balzers Union). The coverslips were attached to stubs with double-sided tape and coated with $20 \mathrm{~nm}$ of gold-palladium. The samples were viewed in a Joel 35CF scanning electronmicroscope.

\section{Results}

\section{Effect of bacterial growth conditions on adherence}

To determine if bacterial growth phase influences the ability of $C$. jejuni isolate M129 to adhere to INT 407 cells, organisms were cultured on MH blood agar medium at $37^{\circ} \mathrm{C}$ for various periods. C. jejuni M129 cells were harvested from the plates after growth for 24, 48 and $72 \mathrm{~h}$ and tested for their ability to adhere to INT 407 cells (fig. 1). Maximal adherence of $C$. jejuni to INT 407 cells was observed with cultures harvested at $24 \mathrm{~h}$. Only slight reductions in adherence were noted

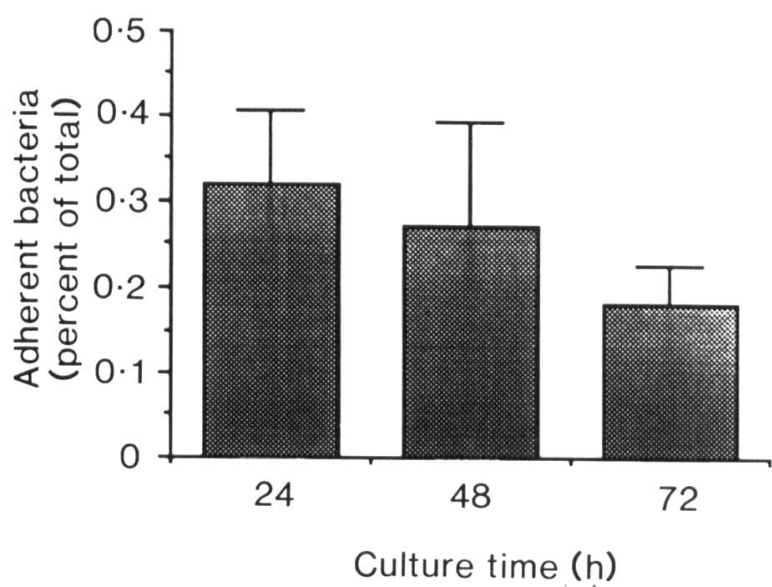

Fig. 1. Adherence to INT 407 cells of $C$. jejuni M129 grown for various times on $\mathrm{MH}$ blood agar plates. The values for a representative assay are the mean percentages of the number of adherent $C$. jejuni in the inocula and were derived from counts of triplicate wells. Error bars represent the $95 \%$ CI of the mean values. Adherence of cultures grown for 24 and $72 \mathrm{~h}$ was significantly different $(\mathrm{p}<0.05)$

for bacteria harvested after incubation for $48 \mathrm{~h}$. However, a significant decrease in adherence was exhibited by cultures incubated for $72 \mathrm{~h}$. Scanning electronmicroscopy revealed significant morphological differences among the cultures (data not shown). Bacteria harvested after $24 \mathrm{~h}$ exhibited a uniform spiral morphology typical of $C$. jejuni, whereas $50 \%$ of the bacteria from the 48 -h culture and $>70 \%$ of bacteria from the 72-h cultures exhibited a rounded morphology. C. jejuni M129 was also cultured in two different types of growth media to determine if medium composition or form affects adherence properties. No significant differences in adherence properties were detected between bacteria harvested from either brain heart infusion liquid medium or MH blood agar plates

C. jejuni was also grown at several different temperatures for $24 \mathrm{~h}$ on $\mathrm{MH}$ blood agar plates and examined for the ability to attach to INT 407 cells (fig. 2).

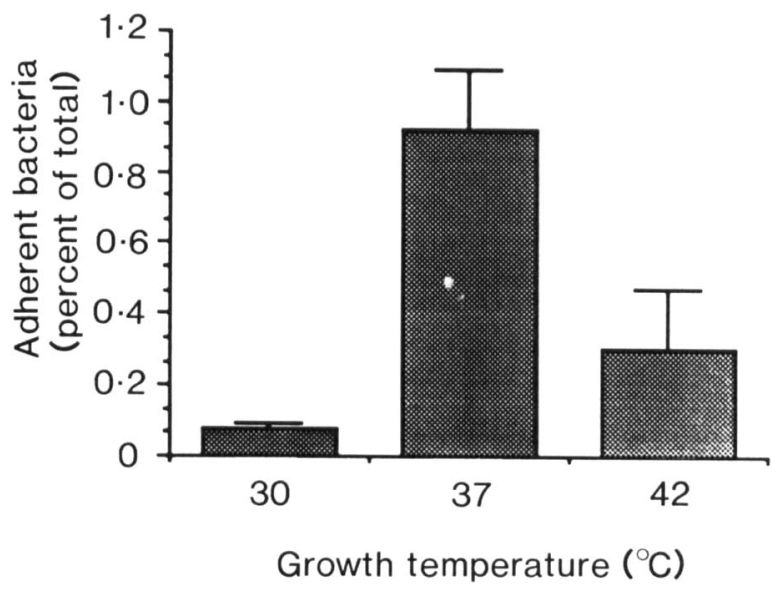

Fig. 2. Effect of bacterial growth temperature on adherence to INT 407 cells of $C$. jejuni M129 grown on MH blood agar. Cells were harvested and assayed for adherence after $24 \mathrm{~h}$. The values for a representative assay are the mean percentages of adherent bacteria in the inocula derived from counts of quadruplicate wells. Error bars represent the $95 \% \mathrm{CI}$ of the mean values. Adherence of bacteria grown at $37^{\circ} \mathrm{C}$ was significantly greater than adherence of organisms grown at either $30^{\circ} \mathrm{C}$ or $42^{\circ} \mathrm{C}(\mathrm{p}<0.05)$. 
Table. Effect of inoculum size on the adherence of $C$. jejuni M129 to monolayer cultures of INT 407 cells

\begin{tabular}{lcc}
\hline $\begin{array}{c}\text { Inoculum size } \\
\text { (ratio) }^{*}\end{array}$ & $\begin{array}{c}\text { Number (SD) of } \\
\text { adherent bacteria } \dagger\end{array}$ & $\begin{array}{c}\text { Percentage of inoculum } \\
\text { adherent } \dagger(\text { SD) }\end{array}$ \\
\hline $1.8 \times 10^{9}(25000: 1)$ & $1.5(0.9) \times 10^{7}$ & $0.83(0.50)$ \\
$9.0 \times 10^{8}(12000: 1)$ & $4.6(0.8) \times 10^{6}$ & $0.51(0.09)$ \\
$2.7 \times 10^{8}(3800: 1)$ & $5.5(1.4) \times 10^{5}$ & $0.21(0.05)$ \\
$3.0 \times 10^{7}(420: 1)$ & $7.0(0.6) \times 10^{4}$ & $0.23(0.02)$ \\
\hline
\end{tabular}

* The values given in parentheses represent the ratio of the number of bacteria to the number of INT 407 cells.

$\dagger$ The values represent the mean of triplicate determinations.

Maximum adherence was observed with bacteria grown at $37^{\circ} \mathrm{C}$. Bacteria grown at $42^{\circ} \mathrm{C}$ exhibited a $66 \%$ decrease, on average, and bacteria grown at $30^{\circ} \mathrm{C}$ exhibited a $91 \%$ decrease in binding when compared to bacteria grown at $37^{\circ} \mathrm{C}$. Scanning electronmicroscopy of individual colonies revealed only minor differences in morphology among the bacteria grown at the different temperatures (data not shown). However, the organisms grown at $30^{\circ} \mathrm{C}$ were slightly more pleomorphic than bacteria grown at the other temperatures.

\section{Kinetics of bacterial adherence}

The number of adherent bacteria after centrifugation of $C$. jejuni on to INT 407 cell monolayers was determined at 15-min intervals for the first hour of incubation and at 30-min intervals for a further $2 \mathrm{~h}$. No significant differences were found in the number of adherent bacteria during the $3-\mathrm{h}$ period. However, the percentage of cell-attached $C$. jejuni increased with inoculum size (table). As the inoculum was increased from $c .1000$ to 25000 bacteria/cell, an increase in the percentage of attached bacteria was observed. The percentage of attached bacteria did not change when the infective dose was less than 1000 bacteria/cell. Accordingly, inoculum ratios of less than 1000 bacteria/cell were used in further experiments. The percentage of HEp-2 cells with attached bacteria was determined by indirect immunofluorescence (fig. 3), and varied from 70 to $100 \%$ depending on the inoculum size. The assays also revealed that the bacteria did not bind evenly over the surface of the cultured cells, but exhibited a patchy distribution characteristic of localised adherence.

\section{Effect of temperature on adherence and internalisation of C. jejuni}

Assay temperature did not have a significant effect on the ability of the bacteria to bind to cultured cells (fig. 4). Although the greatest number of attached bacteria was observed at $4^{\circ} \mathrm{C}$, only slightly fewer adherent bacteria were found at $25^{\circ} \mathrm{C}$ and $37^{\circ} \mathrm{C}$. In contrast, entry of $C$. jejuni into the epithelial cells was temperature-dependent. A decline, by a factor of 1000 , in the number of internalised bacteria was observed when the adherence assay was performed at $4^{\circ} \mathrm{C}$ when compared to binding at $37^{\circ} \mathrm{C}$. As a control, monolayers infected and washed at $4^{\circ} \mathrm{C}$ were then incubated at $37^{\circ} \mathrm{C}$ for $3 \mathrm{~h}$ before addition of gentamicin. Although the number of internalised bacteria was not equal to that in the samples incubated at $37^{\circ} \mathrm{C}$ alone, a sharp increase in the number of internalised bacteria was observed over those cultures incubated only at $4^{\circ} \mathrm{C}$, indicating the reversibility of the effect.

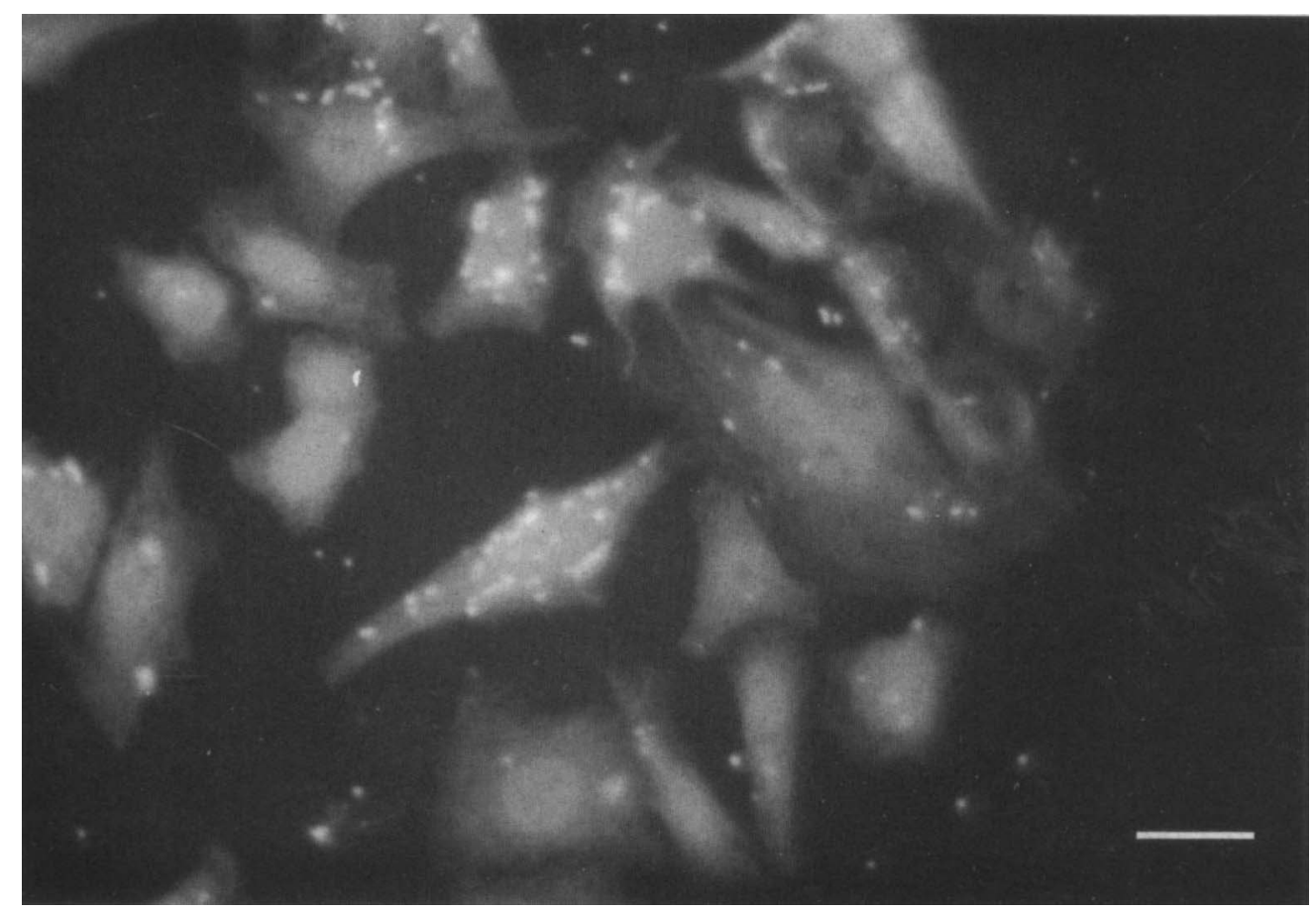

Fig. 3. Indirect immunofluorescence microscopy of a subconfluent monolayer culture of HEp-2 cells inoculated with C. jejuni M129 and processed immediately after centrifugation of the bacteria on to the monolayer. Bar, $20 \mu \mathrm{m}$. 


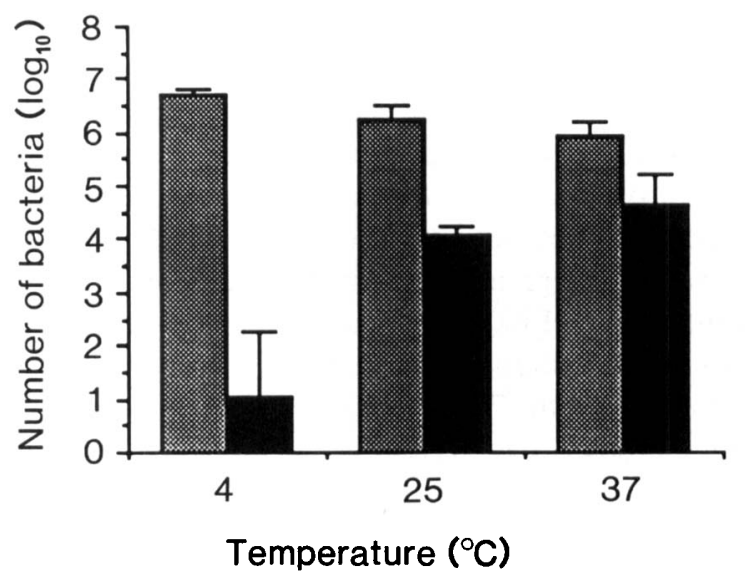

Fig. 4. Effect of temperature on adherence and internalisation in INT 407 cell monolayer cultures inoculated with $C$. jejuni M129 grown at $37^{\circ} \mathrm{C}$ for $24 \mathrm{~h}$ and incubated for $0.5 \mathrm{~h}$ to determine adherence (图) or $3 \mathrm{~h}$ to assess internalisation ( $\square$ ). The values for a representative assay are the means of counts derived from triplicate wells. Error bars represent the $95 \% \mathrm{CI}$ of the mean values. Internalisation at $37^{\circ} \mathrm{C}$ was significantly different from that at $4^{\circ} \mathrm{C}$ $(\mathrm{p}<0.05)$.
Ultrastructural features of $C$. jejuni association with cultured cells

To visualise the interaction of the bacteria with host cells, the samples were examined by scanning electronmicroscopy (fig. 5). Contact between the bacteria and cells appeared to be initiated by the tips of the flagella (fig. $5 \mathrm{~b}, \mathrm{c}, \mathrm{e}$ ). After the initial contact of the bacteria with the host cells, pseudopods extending from the surfaces of INT 407 cells were often observed enveloping the bacteria (fig, $5 \mathrm{~d}$, f).

The non-uniform pattern of adherence revealed by fluorescence microscopy suggested the possibility that C. jejuni binding to epithelial cells might bear similarities to the adherence pattern exhibited by enteropathogenic Escherichia coli (EPEC). Such E. coli strains adhere to HEp-2 cells in a pattern described as localised adherence and induce the accumulation of filamentous actin beneath the sites of attachment. ${ }^{14,15}$ When $C$. jejuni cells were allowed to adhere to HEp-2
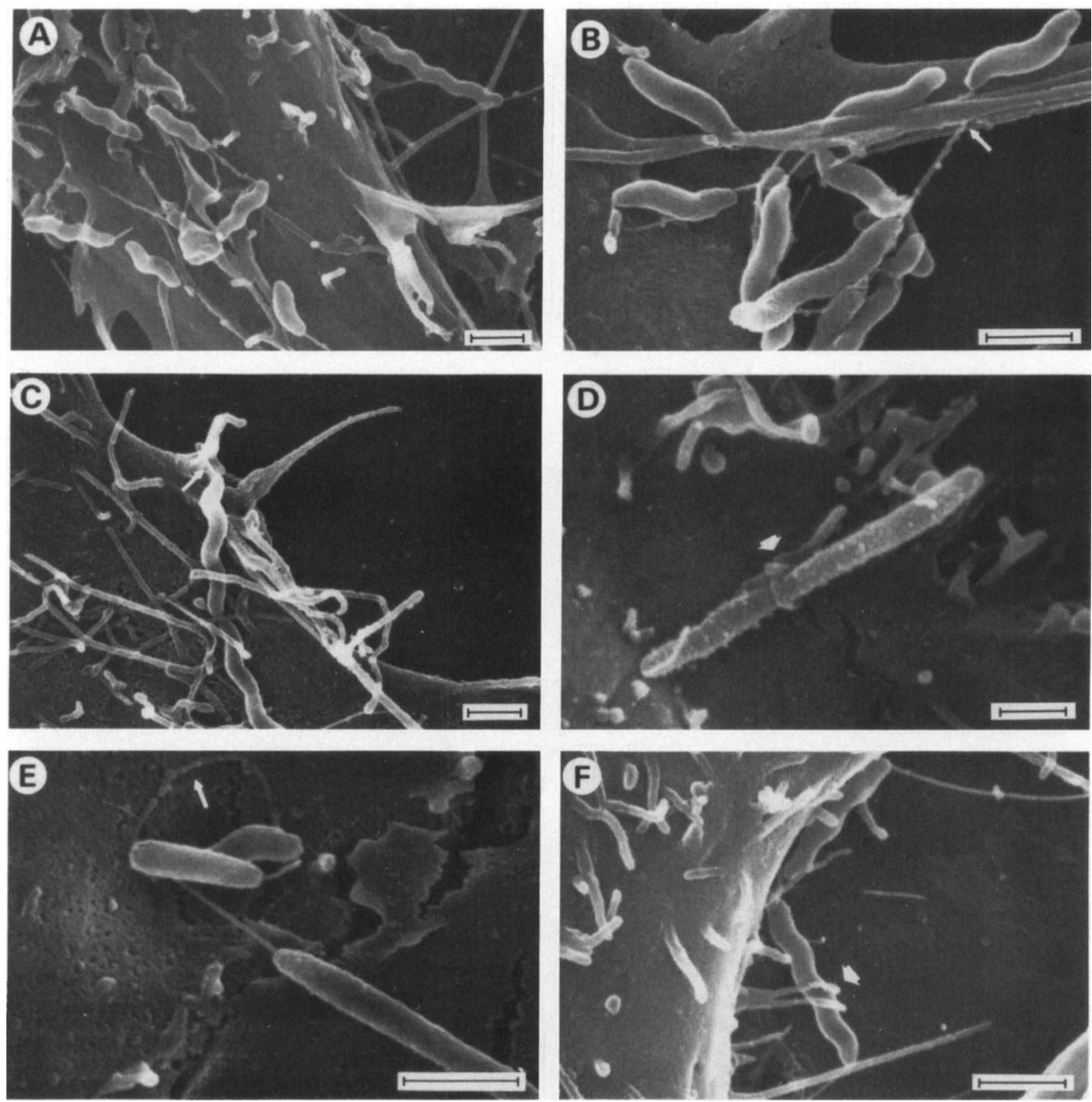

Fig. 5. Interaction of a 24-h culture of $C$. jejuni M129 with monolayer cultures of INT 407 cells. Cultures were washed and fixed immediately after centrifugation $(\mathrm{a}, \mathrm{b})$ or after incubation at $37^{\circ} \mathrm{C}$ for $30 \mathrm{~min}(\mathrm{c}), 60 \mathrm{~min}(\mathrm{~d})$ or $90 \mathrm{~min}(\mathrm{e}, \mathrm{f})$ and processed for scanning electronmicroscopy. The spiral appearance of $C$. jejuni was typical of bacteria harvested from MH agar plates after incubation for $24 \mathrm{~h}$. Thin arrows (in b, c, e) indicate areas where flagella are seen to interact directly with INT 407 cells. Thick arrows (in d, f) indicate pseudopods interacting with the bacteria. Bars, $1 \mu \mathrm{m}$. 


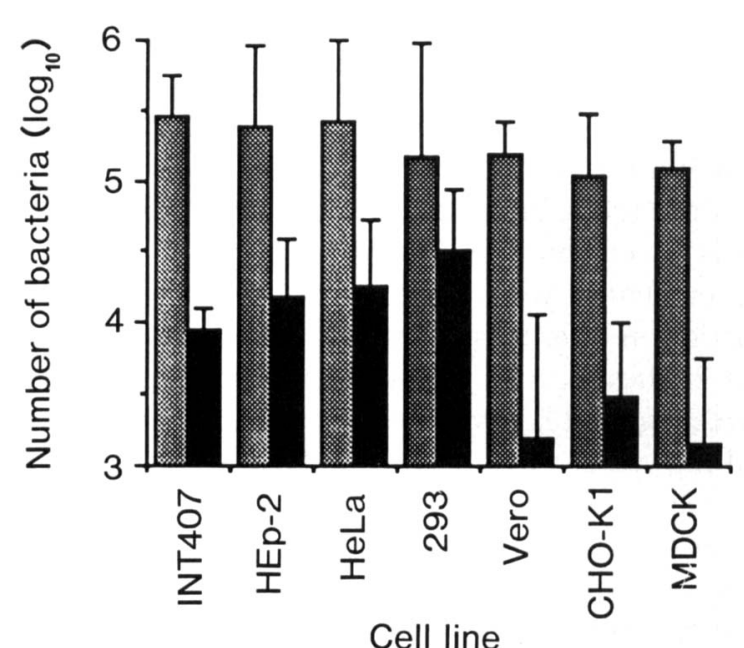

Fig. 6. Attachment and internalisation of $C$. jejuni T6644 to different cell lines. Equal numbers of cells of the cell lines were seeded into 24 well plates, inoculated with $C$. jejuni and assayed for the number of adherent (圈) and internalised ( $\square$ ) $C$. jejuni. The values of a representative assay are the means of counts derived from triplicate wells. Error bars represent the $95 \% \mathrm{CI}$ of the mean values. There were significant differences in bacterial internalisation between the human-derived cell lines (INT 407, HEp-2, HeLa, and 293) and the non-human-derived lines (Vero, CHO-K1, and MDCK) $(\mathbf{p}=0.05$, one-tailed Mann-Whitney U-test).

or INT 407 cells, staining of cellular microfilaments with fluorescein-conjugated phalloidin did not reveal the presence of any dense concentrations of actin in association with the sites of $C$. jejuni attachment or other overt alterations in the distribution of cellular actin.

\section{Adherence and internalisation of $C$. jejuni to various cell lines}

The ability of $C$. jejuni to adhere to and enter various cell lines (INT 407, HEp-2, HeLa, 293, Vero, CHO-K1 and MDCK) was examined to determine if C. jejuni displays preferential interaction with cells of certain tissue or species derivation (fig. 6). C. jejuni isolate T6644 bound to each cell line tested with approximately equal efficiency. However, differences were noted in the number of viable, internalised bacteria with the different cell lines. $C$. jejuni appeared to be most effectively internalised by the epithelial-like cell lines of human origin (INT 407, HEp-2, HeLa, and 293). Both epithelial-like cell lines of non-human origin, MDCK and CHO-K1, appeared to be less effective targets for internalisation, as did Vero, a fibroblast-like cell line. Similar results were obtained with $C$. jejuni isolate M129.

\section{Discussion}

The structural and molecular bases for $C$. jejuni adherence to epithelial cells are ill-defined. The specific roles of flagella, lipopolysaccharide, and outer-membrane components in adherence remain conjectural. ${ }^{8}$ While the relevance of in-vitro observations of $C$. jejuni adherence to cultured epithelial cells in relation to the pathobiological behaviour of the bacteria in vivo is not known, it is likely that adherence to such types of cells is important to the ability of $C$. jejuni to colonise the human gastrointestinal tract. Furthermore, adherence and internalisation may be the primary virulence mechanisms that result in the overt manifestations of $C$. jejuni-mediated enteritis, including diarrhoea and inflammation. In-vitro models offer the advantage that parameters that could possibly influence the ability of organisms to interact with mammalian cells may be readily manipulated, thus allowing the evaluation of conditions that might lead to altered expression of virulence determinants. It is well known that bacterial culture conditions influence the expression of virulence determinants of other pathogenic bacteria. ${ }^{16}$ In this study, the effects of culture conditions and assay parameters were examined to determine if they affect the ability of $C$. jejuni to adhere to and enter cultured mammalian cells, and we have described the distribution and ultrastructural features of $C$. jejuni adherence to epithelial cells.

C. jejuni harvested from earlier phases of growth exhibited greater adherence to INT 407 epithelial cells than did bacteria obtained from older colonies (e.g., $72 \mathrm{~h}$ ). Colonial age has also been reported to affect the adherence of Vibrio parahaemolyticus to human fetal intestinal cells. ${ }^{17}$ Bacterial growth temperature also had a marked effect on the ability of $C$. jejuni to bind to INT 407 cells. A significant and reproducible increase in $C$. jejuni adherence to INT 407 cells was observed when organisms were grown at $37^{\circ} \mathrm{C}$ rather than at either $30^{\circ} \mathrm{C}$ or $42^{\circ} \mathrm{C}$. We do not believe that the increase in pleomorphic morphology observed amongst organisms grown at $30^{\circ} \mathrm{C}$ is, in itself, significant, because morphological alterations attendant to bacterial cultures grown for $48 \mathrm{~h}$ at $37^{\circ} \mathrm{C}$ did not appear to affect adherence. It is possible that temperature-dependent selection of less adherent variants occurs at either higher or lower temperatures. Different growth temperature may result in altered synthesis or deposition of bacterial surface components that affect adherence through specific binding or through the alteration of surface hydrophobicity or charge. Walan and Kihlström ${ }^{18}$ found that clinical isolates of $C$. jejuni with a high net negative charge and a weakly hydrophobic surface showed a greater tendency to adhere to human intestine HT-29 cells than strains with a less negative charge and a more hydrophobic surface. It is also noteworthy that we have been able to detect both qualitative and quantitative changes in the surface protein profile of $C$. jejuni isolates grown at various temperatures, as judged by cell surface radio-iodination (W. Cieplak and M. E. Konkel, unpublished observations). The effect of growth temperature on deposition of surface proteins and adherence may indicate the presence of a regulatory system that is directly affected by temperature and acts on one or more structural genes. Such temperature-dependent regulatory systems have been described for Bordetella, 
Shigella and Yersinia spp. ${ }^{16}$ Accordingly, we are continuing to examine the extent to which growth temperature affects the surface properties of $C$. jejuni.

Indirect fluorescence microscopy was used to determine the pattern of $C$. jejuni binding to epithelial cells. $C$. jejuni did not bind diffusely to the surface of HEp-2 cells, but rather bound in a localised manner. This may be a reflection of the distribution of surface constituents to which the organisms bind. Localised adherence has also been observed with Helicobacter pylori binding to HGT1 cells, a gastric cell line.$^{19} C$. jejuni appears to bind to HEp-2 cells in a fashion similar to that exhibited by certain strains of enteropathogenic E. coli (EPEC), specifically those serogroups which are most commonly associated with diarrhoeal disease. ${ }^{20}$ The attachment of EPEC strains to HEp-2 cells produces an attaching and effacing lesion that is characterised by dense concentrations of microfilaments which accumulate beneath the sites of attached bacteria. ${ }^{14,15}$ However, attachment of $C$. jejuni to HEp-2 cells did not produce an actin accumulation characteristic of the formation of attaching and effacing-type lesions.

Direct visualisation of infected cells by scanning electronmicroscopy revealed that the flagella may be involved in mediating the attachment of $C$. jejuni to host cells. McSweegan and Walker ${ }^{6}$ found that removal of the flagella by shearing reduced $C$. jejuni adherence to INT 407 cells, whereas treatment of the bacteria with $\mathrm{KCN}$ to immobilise the flagella increased adhesion. We have also observed a reduction in adherent $C$. jejuni when they are subjected to mechanical shearing before inoculation of INT 407 cell monolayers; however, the reduction was not observed when the bacteria were centrifuged on to the cell monolayers, suggesting that flagella promote adherence by facilitating cell contact through motilitydependent mechanisms (M. E. Konkel and W. Cieplak, unpublished observations). Our current efforts are directed at assessing the contribution of flagella to binding through the use of stable, nonflagellate mutants and their isogenic counterparts. Electronmicroscopic observations of colonies of $C$. jejuni also revealed the presence of flocculent extracellular material that appeared to be loosely associated with the bacterial cell surface (M. E. Konkel and S. F. Hayes, unpublished observations). This material is lost during the washing procedures employed in the preparation of bacteria for the adherence assay as judged by its absence on washed cells. The loosely associated extracellular material that was observed on freshly prepared, unwashed bacteria by electronmicroscopy did not have a significant effect on binding as judged by the failure of unwashed bacteria to exhibit reproducible increases or decreases in adherence to the cell lines employed. The biochemical nature of this material is unknown.
Scanning electronmicroscopy revealed that host cell pseudopods interact directly with attached $C$. jejuni. This event appeared to be a pre-requisite for bacterial internalisation. Consistent with active target cell participation, the internalisation of $C$. jejuni by INT 407 cells is a temperature-dependent event. When cells were incubated with $C$. jejuni at $4^{\circ} \mathrm{C}$, a significant reduction in internalised bacteria was observed. Previous studies with $C$. jejuni have demonstrated that host cell microfilaments actively participate in bacterial entry. Cytochalasin B inhibits the internalisation of $C$. jejuni by various cells in a dose-dependent manner. ${ }^{11,21}$ Lack of entry at low temperature and the involvement of cellular pseudopods in entry have been observed during the interaction of $Y$. pseudotuberculosis with HeLa cells. ${ }^{22}$

Finally, $C$. jejuni were tested for their ability to bind to human and non-human cell lines. Although the bacteria were found to bind to each cell line with equal efficiency, a greater number of internalised viable $C$. jejuni were found when cells of human origin were employed. The difference did not appear to be necessarily attributable to the tissue origin of the target cell or morphological appearance (epithelial-like vs fibroblast-like). Possible explanations for this finding are that the non-human-derived cell lines may express different types or amounts of binding components or that $C$. jejuni survival is increased in human-derived cell lines after internalisation. The apparent preference of human- over non-human-derived cell lines in internalisation may be relevant to the difficulty in establishing a simple, reproducible animal model of $C$. jejuni-mediated disease. Finding a non-human cell line which is capable of internalising $C$. jejuni with an efficiency equal to human-derived cell lines may help to identify a suitable animal model for human disease.

In-vitro models have been used with increasing frequency to study the adherence properties of $C$. jejuni. However, the methodology associated with such assays has, to a certain extent, lacked uniformity. For example, inocula have been prepared from $C$. jejuni grown at various temperatures $\left(37^{\circ} \mathrm{C}\right.$ or $42^{\circ} \mathrm{C}$ ) and assays have utilised various cell types. ${ }^{6,7,11,21,22}$ This study has helped to identify the conditions that influence the interactions of $C$. jejuni with cultured mammalian cells and described their basic features. The results suggest that undefined variables associated with both the bacteria and cultured target cells affect adherence and internalisation. We are currently attempting to identify, in molecular terms, the factors responsible for mediating the binding and internalisation of $C$. jejuni by cultured mammalian cells.

We thank Drs H. Caldwell and S. Fischer for helpful comments and critical reading of the manuscript. We also thank R. Evans and G. Hettrick for assistance with preparation of the graphics. 


\section{References}

1. Blaser MJ, Wells JG, Feldman RA, Pollard RA, Allen JR, and the Collaborative Diarrheal Disease Study Group. Campylobacter enteritis in the United States. Ann Intern Med 1983; 98: 360-365.

2. Calva E, Torres J, Vazquez M, Angeles V, de la Vega H, RuizPalacios GM. Campylobacter jejuni chromosomal sequences that hybridize to Vibrio cholerae and Escherichia coli LT enterotoxin genes. Gene 1989; 75 : 243-251.

3. Daikoku T, Kawaguchi M, Takama K, Suzuki S. Partial purification and characterization of the enterotoxin produced by Campylobacter jejuni. Infect Immun 1990; 58 : 2414-2419.

4. Klipstein FA, Engert RF, Short H, Schenk EA. Pathogenic properties of Campylobacter jejuni: assay and correlation with clinical manifestations. Infect Immun 1985; 50: 43-49.

5. Yeen WP, Puthucheary SD, Pang T. Demonstration of a cytotoxin from Campylobacter jejuni. J Clin Pathol 1983; 36: $1237-1240$.

6. McSweegan E, Walker RI. Identification and characterization of two Campylobacter jejuni adhesins for cellular and mucous substrates. Infect Immun 1986; 53: 141-148.

7. Fauchere JL, Rosenau A, Veron M, Moyen EN, Richard S, Pfister A. Association with HeLa cells of Campylobacter jejuni and Campylobacter coli isolated from human feces. Infect Immun 1986; 54: 283-287.

8. Fauchère J-L, Kervella M, Rosenau A, Mohanna K, Veron M Adhesion to HeLa cells of Campylobacter jejuni and C. coli outer membrane components. Res Microbiol 1989; 140: 379-392.

9. McSweegan E, Buff DH, Walker RI. Intestinal mucus gel and secretory antibody are barriers to Campylobacter jejuni adherence to INT 407 cells. Infect Immun 1987; 55: $1431-1435$.

10. Buck GE, Parshall KA, Davis CP. Electron microscopy of the coccoid form of Campylobacter jejuni. J Clin Microbiol $1983 ; 18$ : $420-421$.
11. Black RE, Levine MM, Clements ML, Hughes TP, Blaser MJ. Experimental Campylobacter jejuni infection in humans. $J$ Infect Dis 1988; 157: 472-479.

12. Konkel ME, Joens LA. Adhesion to and invasion of HEp-2 cells by Campylobacter spp. Infect Immun 1989; 57: 2984-2990.

13. Falkow S, Small P, Isberg R, Hayes SF, Corwin D. A molecular strategy for the study of bacterial invasion. Rev Infect Dis 1987; 9: S450-S455.

14. Knutton S, Baldwin T, Williams $\mathrm{PH}$, McNeish AS. Actin accumulation at sites of bacterial adhesion to tissue culture cells: basis of a new diagnostic test for enteropathogenic and enterohemorrhagic Escherichia coli. Infect Immun $1989 ; 57: 1290-1298$.

15. Jerse AE, Yu J, Tall BD, Kaper JB. A genetic locus of enteropathogenic Escherichia coli necessary for the production of attaching and effacing lesions on tissue culture cells. Proc Natl Acad Sci USA 1990; 87: 7839-7843.

16. Finlay, BB, Falkow, S. Common themes in microbial pathogenicity. Microbiol Rev 1989: 53: 210-230.

17. Hackney CR, Kleeman EG, Ray B, Speck ML. Adherence as a method for differentiating virulent and avirulent strains of Vibrio parahaemolyticus. Appl Environ Microbiol 1980; 40 : $652-658$.

18. Walan $\AA$, Kihlström E. Surface charge and hydrophobicity of Campylobacter jejuni strains in relation to adhesion to epithelial HT-29 cells. APMIS 1988; 96: 1089-1096.

19. Neman-Simha V, Mégraud F. In vitro model for Campylobacter pylori adherence properties. Infect Immun 1988; 56 : 3329 3333.

20. Scaletsky ICA, Silva MLM, Trabulsi LR. Distinctive patterns of adherence of enteropathogenic Escherichia coli to HeLa cells. Infect Immun 1984; 45: 534-536.

21. de Melo MA, Gabbiani G, Pechére J-C. Cellular events and intracellular survival of Campylobacter jejuni during infection of HEp-2 cells. Infect Immun 1989; 57: 2214-2222.

22. Brunius, G, Bölin, I. Interaction between Yersinia pseudotuberculosis and the HeLa cell surface. J Med Microbiol $1983 ; 16$ : 245-261. 